OPEN ACCESS

Edited by:

Sarah Marrs,

Virginia Commonwealth University,

United States

Reviewed by:

Päivi Kristiina Hökkä,

University of Jyväskylä, Finland

Balwant Singh,

Partap College of Education, India

*Correspondence:

Heidi Salmento

heidi.salmento@utu.fi

Specialty section:

This article was submitted to

Teacher Education,

a section of the journal

Frontiers in Education

Received: 24 August 2021

Accepted: 25 October 2021

Published: 08 November 2021

Citation:

Salmento H, Murtonen M and Kiley M (2021) Understanding Teacher Education Students' Research

Competence Through Their

Conceptions of Theory.

Front. Educ. 6:763803.

doi: 10.3389/feduc.2021.763803

\section{Understanding Teacher Education Students' Research Competence Through Their Conceptions of Theory}

\author{
Heidi Salmento ${ }^{1 *}$, Mari Murtonen ${ }^{1}$ and Margaret Kiley ${ }^{2}$ \\ ${ }^{1}$ Department of Teacher Education, University of Turku, Turku, Finland, ${ }^{2}$ Adjunct, Research School of Humanities and the Arts, \\ The Australian National University, Canberra, ACT, Australia
}

Learning a scientific way of thinking is a fundamental aim of university education. It means that there are certain thinking skills that students across all disciplines should learn during their studies. For example, critical thinking and reasoning skills are essential for all university graduates. In addition, students are expected to achieve certain skill levels related to scientific research, for example: learning the basic concepts of science and research methodology, understanding the research process and understanding the nature and origins of scientific knowledge. We call these skills research competence and see research competence as one of the main elements of scientific thinking. We assume that understanding the basic concepts of science is a starting point for the development of research competence and more broadly, for scientific thinking. However, previous studies have shown that scientific concepts are not easy for students to learn. The aim of this study is to increase our understanding of a particular aspect of university students' research competence by exploring teacher education students' ( $N=179)$ conceptions of one of these challenging concepts, the concept of theory. The results illustrate that understanding the concept of theory is challenging even for graduating (fourth and fifth year) master students. Only half of them were able to describe the concept of theory in a scientific context suggesting that the other half had unscientific conceptions of theory, named here as non-scientific conceptions. When looking at the students' who reported scientific conceptions of theory, one quarter of graduating students and a few early stage (first and second year) students had a declarative approach meaning that they were able to describe the concept of theory by using some basic scientific terms. About one fifth of graduating and early stage students had a procedural approach meaning that they were able to describe theory related to research as "doing". Only a small number of students showed an understanding of the nature and origins of scientific knowledge and the role of research and theory, called here an epistemic approach.

Keywords: research competence, conceptions of theory, epistemic understanding, scientific thinking, scientific thinking skills, higher education, research skills 


\section{INTRODUCTION}

Information of many kinds is growing exponentially and social media allows us to share it incredibly quickly. People around the world make decisions based on news and research shared by other social media users. Separating fake news or fake research from scientific reports is difficult without the skills to understand scientific research. Thus, critical thinking skills (see e.g. Hyytinen, Toom \& Shavelson, 2019) and skills to understand research have become more important than ever before. These skills are especially important for students who are graduating from universities and who will work as experts in their field in the future (Murtonen \& Balloo, 2019). Previous research (Murtonen \& Salmento, 2019) has shown that there are certain thinking skills that can be seen as common learning goals for university students in all disciplines. We call these scientific thinking skills. Traditionally, scientific thinking has been understood quite narrowly and the words "science" and "scientific" are often associated only with natural sciences. However, when talking about scientific thinking we refer to all disciplines of universities. Based on the theory of scientific thinking in higher education (Murtonen \& Salmento 2019), both university teachers and students emphasise the role of research skills (or research competence) as a fundamental part of scientific thinking. The other aspects of the theory were critical thinking skills, epistemic understanding (skills to understand the nature and sources of knowledge), evidence-based reasoning and contextual understanding (disciplinary and more generic understanding in situating knowledge).

\section{Research Competence in University Education}

Earlier research suggests that teacher education students are not always able to connect the theoretical parts of their studies with practice (Puustinen, Säntti, Koski \& TammiMurtonen, Olkinuora, Tynjälä \& Lehtinen, 2008;2018; van Katwijk, Berry, Jansen, \& van Veen, 2019). However, students are expected to learn certain research skills during their university education, called here research competence. There is variation in how research competence is defined in the literature. Some of the studies concentrate on disciplinary specific competencies (see e.g. Valter \& Akerlind, 2010) and some concentrate more on some phase of research process (see e.g. Chang, Chen, Guo, Cheng, Lin \& Jen, 2011). Some researchers have approached the phenomena more generally and for example Thiel and Böttcher (2014) have created a model presenting research competences across various academic disciplines (see also Böttcher \& Thiel, 2018). According to their findings, regardless of discipline, higher education students' research competences comprise for example content knowledge, skills in reviewing the state of research, methodological skills, skills in reflecting on research findings and communication skills.

Previous studies have shown that university students face many difficulties in learning research skills (Earley, 2014; Wagner, Garner \& Kawulich, 2011) and even the most central concepts are not easy for students to learn (Murtonen, Aiston \&
Kiley 2006; Murtonen, 2015; Kiley \& Wisker, 2009). For example, students in bachelor's and master's programmes have been reported to have substantial problems in the learning of the central conceptions of research methods, such as theoretic and empiric concepts (Murtonen 2015). We assume that understanding the most central scientific concepts, like concept of theory in this study, is a starting point to be able to learn more advanced research skills and thus, forms a starting point for research competence. Because university teachers are very familiar with these concepts, it may sometimes be difficult for them to understand that they are challenging for students to learn. Also, some teachers see students' research skills as more important than others and use different teaching methods to support their students' learning (Brew \& Mantai, 2017; Lorencová, Jarošová, Avgitidou \& Dimitriadou, 2019; Brew \& Saunders, 2020). As Balloo (2019) states, teachers should be aware of the issues with which their students struggle in methodological courses and pay attention to see if the pedagogical approaches they are using are likely to help students to get over the possible barriers.

\section{Understanding the Concept of Theory}

Defining the concept of theory is not unambiguous because the concept is used in many different ways (Kiley 2015, 52; Kuhn \& Pearsall 2000, 116; Murtonen et al., 2006, 142; Tight 2015, 86). Many concepts are understood differently in everyday speech and within academic communities. Understanding the scientific meaning of the concept of theory may be difficult for students because of the way the concept is used in everyday speech, which is more familiar to them than in academic use, especially at the beginning of their studies. According to Kuhn (2010) very young children begin to organize their experience by constructing theories, and the coordination of theory and evidence is common both for early theory revision and scientific thinking. What is different between these is that the early theory revision often occurs implicitly without conscious awareness while scientific thinking is associated with conscious activity. Thus, university students need to have opportunities to deliberately practise to understand and use the concept of theory. In earlier work Kiley and Wisker (2009) argued that theory was one of several threshold concepts in learning to be a researcher (see also Kiley, 2019). As Meyer \& Land (2006) proposed, a threshold concept is "something distinct within what university teachers would typically describe as "core concepts" (p. 6). They elaborated by suggesting that the characteristics of a threshold concept are likely to be transformative, irreversible, integrative, (possibly) bounded in any conceptual space, and (potentially) troublesome (pp. 7-8). Hence, as outlined below, the concept of theory was considered to be critical for research students to fully understand in order for them to progress and develop as researchers.

Based on a previous study (Murtonen, 2015) there are differences at least in students' conceptions of the origins and the aim of theory. Students may have problems for example in understanding what theories are, where they come from and what 
they are needed for. Additionally, students may have very different conceptions of theory and it is likely that many of these arise from the non-scientific way of using the word theory in everyday language. For example, in daily speech it is common to see theory and practice separated from each other. This is quite general and students may have difficulty understanding the link between theory and practice especially in the beginning of their university studies. Furthermore, they may be confused by the role of theory, and as Knight (2015) argues, it is common for students to hope that there was 'more practice rather than theory' in their studies. According to him the suggestion that the conception of theory is something that is separated from practice can be seen in the literature. Previous studies have reported, for example that teacher education students have difficulties understanding the value of integrating theory to classroom practice (Knight, 2015, 145) On a positive note, however, according to Knight's (2015) findings, students seem to eventually find the value of theory if given time.

Another conception that is general in everyday thinking is the idea that theories are there to explain practice, for example people's behavior, different phenomena or events, without requiring any scientific evidence. Students may also be confused where the theories come from. They may have many different kinds of thoughts about the essence of theory, whether theories are certain or uncertain, and whether they are stable or able to change over time. In this way students' conceptions of theory are linked also with their epistemological beliefs (Salmento \& Murtonen 2019), that is, beliefs about knowledge and knowing (see for example, Kuhn \& Weinstock 2002; Nussbaum, Sinatra \& Poliquin, 2008). Theories can be seen as existing products created by others or as a fact or truth. For example, the grand theories like Darwin's theory of evolution or Einstein's theory of relativity are often understood in that way. Students may find it difficult to understand that new theories can be generated on the basis of each study and research can change the existing theories. During their university studies students need to develop an understanding that the existing theories are able to change and new theories are emerging all the time. It would be important for students to understand that the existing theories are used as a theoretical framework for research and in addition, new theories can be created through the results of the new research.

\section{Research Competence and Conceptions of Theory}

Understanding the link between theory and research is causing problems for students as well (Kiley 2015; Murtonen 2015). According to Murtonen (2015) theory and research are often linked together, but the link is not unequivocal. Creation or modification of theories can be seen as the aim of research. In a study by Murtonen (2015), some students made a link between qualitative research and theory in the meaning that qualitative research produces theory while some students made a link between quantitative research and theory in a sense that in quantitative research theories are tested. What made these linkages problematic was that some students thought 'theoretical' is only connected to qualitative or quantitative research but not to both. Theory can also be seen as bringing credibility and reliability to research. Kiley (2015) reported in her study that research supervisors reported that it was not uncommon for doctoral candidates to experience difficulties understanding the concept of theory and appreciating the role of theory in research. For example, it was reported that candidates experienced difficulties in using theory as a framework for research, and also in forming a new theory based on research. Given a widespread view of the importance of understanding the concept of theory, and also being able to use theory in research, Kiley argued that this is critical for the development of a researcher.

As described above, many concepts are understood differently in everyday life compared with a scientific context and we assume that it is common for students to have everyday conceptions of scientific concepts especially in the beginning of their studies. Understanding the concepts at an everyday level is a starting point and university studies can then support students to move forward and learn to understand the scientific meaning of these concepts. The results of a previous study analyzing university students' conceptions of research (Salmento \& Murtonen, 2019) revealed that there are different levels of how students' understand research. Some students had conceptions at the lowest, declarative level, meaning that they used some core concepts of scientific research, e.g. objectivity and repeatability when talking about research. Some students had conceptions at a more advanced, procedural level meaning that their conceptions were related to doing, for example participating in, or conducting research. Some students were able to describe research at the most advanced, epistemic level. These students have the understanding to reflect the nature and sources of scientific knowledge and show understanding that even scientific knowledge is uncertain and created by people. We assume that reaching the declarative level (understanding the core concepts of scientific research) is a requirement to be able to move onto the procedural level (to be able to participate on scientific knowledge construction) and reaching both of these levels is a requirement for being able to move to the next, the epistemic level (understanding the nature and sources of scientific knowledge).

The aim of this study is to increase our understanding of teacher education students' research competence by exploring how they understand one of the most fundamental scientific concepts; the concept of theory. By exploring how students' comprehend the concept of theory, one of the core concepts of science, we aim to increase our understanding of how well teacher education students really handle the concept and if there is a need to pay more attention to how university teachers could support their students to develop their understanding of this kind of core concept. On the basis of the scarce prior research on this area, it appears that the concept of theory has been found to be difficult to understand for masters level students (Murtonen, Aiston \& Kiley 2006; Murtonen, 2015) and even for doctoral students (Kiley \& Wisker, 2009). In this study we aim to explore at which levels students understand the concept of theory and if there are differences between students' conceptions at different phases of their studies. 


\section{Given This Background the Research Questions Are}

1. What kind of conceptions of theory teacher education students have?

2. Are there differences in conceptions of theory between early stage (first or second year) students and graduating (third or fourth year) students?

\section{MATERIALS AND METHODS}

The participants $(\mathrm{N}=179)$ of this study were Finnish teacher education students. Of the participants, 114 were first or second year students (called here early stage students) and 65 were fourth or fifth year students (called here graduating students). The data was collected by a questionnaire consisting of background information and an open-ended question. Background questions consisted of age, sex, and study year and the openended question was: "What do you think the concept of theory means? Describe shortly in your own words". Approximately two thirds of the participants $(\mathrm{N}=126)$ answered by completing a traditional paper-and-pencil hard copy questionnaire. The first author of this study visited their lectures and told them some basic things about the research and all of the students received the same information before responding to the questionnaire. About one third of the students $(\mathrm{N}=53)$ completed the questionnaire online. They received the same instructions by email. Students were informed that the aim of the research is to explore what they think about some certain concepts. They were told that answering is voluntary and the data will be stored, analyzed and reported by following the university's ethical recommendations and instructions.

\section{Data-Analysis}

Firstly then students' open-ended answers were transcribed and the data was anonymized by giving an ID-number for each student and then entered into IBM SPSS statistics program. Variables were created also for background information including study year. As detailed below, conceptions of theory were entered by using codes 1 (non-scientific conceptions), 2 (scientific conceptions in declarative level), 3 (scientific conceptions in procedural level) and 4 (scientific conceptions in epistemic level). Differences in conceptions of theory between early stage (first and second year) students and graduating (fourth and fifth year) students were explored by crosstabulations. The length of students' answers varied between 3-104 words and the total of the transcribed answers was 15 pages. The answers were read and analysed to answer the research question "What kind of conceptions teacher education students have of the concept of theory". Two researchers read the answers and created individually a preliminary categorisation of the answers. Then, categorisations were compared and a final categorisation was created. It was clear that the data driven analysis showed that there were two kinds of answers: 1) answers, that did not include any scientific concepts and were more related to everyday-conceptions, like explaining practice, being a solution to some practical problem or being a fact or truth and 2) answers that showed some kind of understanding of the concept of theory in a scientific context. Thus, the categoristation was made firstly by separating the answers in two main categories: 1) nonscientific conceptions and 2) scientific conceptions of the concept of theory. Then, the answers that were categorized to the category scientific conceptions were analysed in more detail.

According to previous research results (Salmento \& Murtonen, 2019), students' understand, or are able to describe research at three different levels: 1) declarative, 2) procedural and 3) epistemic. Although these original categorizations were based on conceptions of research, the idea of the categorization showed to be applicable to conceptions of theory. Thus, in this study, students' answers that showed scientific conceptions of the concept of theory were categorized by utilizing the idea of these levels. Thus, three sub-categories for scientific conceptions of theory were created and were named as declarative level, procedural level and epistemic level. The categorization was conducted by a topdown method meaning, that when reading each answer the researcher checked first, to see if the answer reached the highest, epistemic level. If it did, the answer was categorized to this category. If not but when checked it reached the next, procedural level it was then categorized to the procedural category. If not, when checked and the answer reached the lowest level that is declarative level it was categorized to this category. However, if the answer could not be categorized to one of these three categories, then in conjuction with a coreseacher it was considered whether the answer should have been categorised as a non-scientific conceptions already in the beginning of the analysis. Note, however, that these cases were scarce in this study.

We assume that these categories describe the developmental stages, meaning that one must have reached declarative level before to be able to understand the concept in procedural level and both declarative and procedural level must have been reached before to be able to understand the concept in epistemic level. In this study we were interested in the level of their current conceptions. Each answer was categorized to only one category because the aim of the analysis was to find out in which of these levels each student's conceptions currently stand, i.e. what it the highest of these levels that each student's answer reaches. The first and the second author of this study analysed $30 \%$ of the data by coding the answers on the basis of the categorisation. Inter-rater reliability was $86 \%$. The first author analysed the rest of the data. The idea of categorization is explained more detailed in Figure 1.

\section{RESULTS}

\section{Students' Conceptions of Theory}

The analysis of students' open-ended answers showed that there are clear differences in how they understand the concept of 


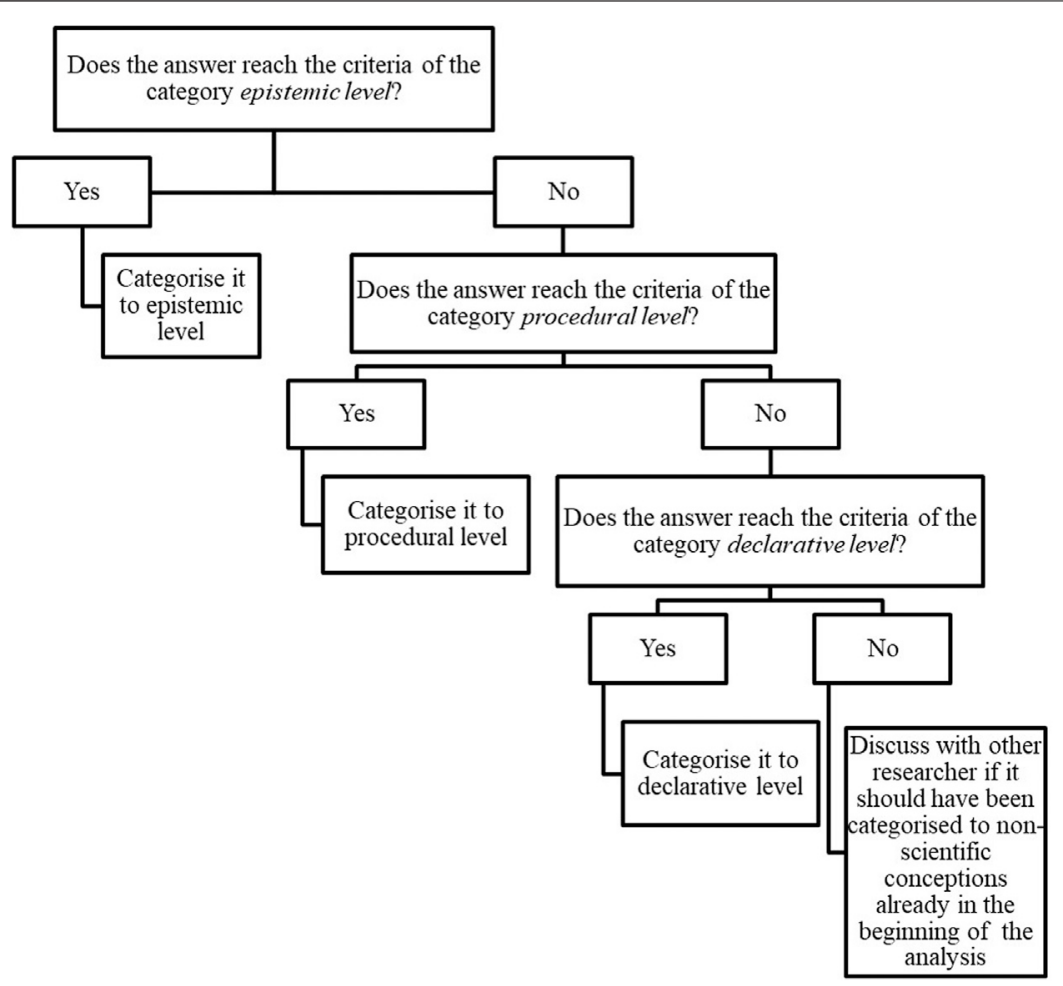

FIGURE 1 | The categorization of students' scientific conceptions of theory.

TABLE 1 | Examples of students' answers in the category non-scientific conceptions.

Non-scientific conceptions

"Theory is knowledge about something. Theory is explaining practice." (4)

"...the opposite of concreteness." (6)

"Truth about something, why something is in the way it is or happens in a certain way." (26)

"That it is not real or based on facts." (34)

"Theory is an explanation or solution to a problem." (37)

"Justified point of view" (56)

"Belief or assumption about how something happens" (59)

"Theory is a view of how something in practise, for example certain kind of behavior is possible, where it comes from and where it leads." (103)

theory. The most notable difference was that some of the answers showed the understanding of the concept of theory in a scientific context, but many of the answers did not. Instead, they were more related to 'everyday thinking' and did not show any kind of understanding of the concept of theory in its scientific meaning. These students seemed to combine the concept of theory to practical thinking in everyday life, for example explaining practice, being a solution to some problem or being a fact or truth. The first category, named as non-scientific conceptions was created for this kind of conceptions. Examples of students' answers classified to this category are presented in Table $\mathbf{1}$.

The rest of the answers, that is, answers that showed understanding the concept of theory in a scientific context were analysed in more detail. The data driven analysis revealed that some of the answers showed deeper understanding than the others. Some were very declarative and quite superficial and some were more advanced and showed some kind of understanding of how and where theories come from (i.e. the relation between research and theories, related to doing). Some of the answers showed deeper understanding of the concept of theory and the nature and origins of scientific knowledge. Similar kinds of differences between students' answers were found in a previous study exploring students' conceptions of research (Salmento \& Murtonen, 2019). The basic idea of three-step categorization (declarative, procedural and epistemic level) that was created in that study for university students' conceptions of research showed to be applicable also to students' conceptions of theory. Thus, in this study students' answers that showed scientific conceptions of the concept of theory were categorized by utilizing the basic idea of these levels. Students' answers showing conceptions of theory in scientific context were classified to following categories: 
TABLE 2 | Examples of students' answers in the categories declarative, procedural and epistemic level.

\begin{tabular}{|c|c|c|}
\hline Declarative level & Procedural level & Epistemic level \\
\hline $\begin{array}{l}\text { "Scientific description of some issue, defined at } \\
\text { conceptual level" (44) }\end{array}$ & "Knowledge that is based on reseach results" (16) & $\begin{array}{l}\text { "A conception of how some phenomena occurs based on } \\
\text { researchers. Theory is always a context based view of the } \\
\text { phenomena and it's made from the viewpoint of some } \\
\text { certain researcher." (19) }\end{array}$ \\
\hline $\begin{array}{l}\text { "Abstract, scientific model for how some } \\
\text { phenomena appears and works in the } \\
\text { world." (74) }\end{array}$ & $\begin{array}{l}\text { "A combination of definitions and studies concentrating on } \\
\text { certain topic. For example Evolution theory includes } \\
\text { concepts and studies that form the theory" (43) }\end{array}$ & $\begin{array}{l}\text { "Theory can be seen as a pattern or solution to the } \\
\text { phenomena that is under research. It explains and specifies. } \\
\text { There are several theories for the same phenomena. Theory } \\
\text { is a research result made by one or several people." (96) }\end{array}$ \\
\hline $\begin{array}{l}\text { "Theory is a scientific model to explains } \\
\text { things." (86) }\end{array}$ & $\begin{array}{l}\text { "Theory means gathered knowledge of some thing or } \\
\text { phenomena, and theory is aiming to explain that with the } \\
\text { help of research" (106) }\end{array}$ & $\begin{array}{l}\text { "Theory is that knowledge that has been received on the } \\
\text { grounds of research. Theory is generalized knowledge. New } \\
\text { studies can be done based on theory and thus the theory } \\
\text { can be broadened." (98) }\end{array}$ \\
\hline $\begin{array}{l}\text { "Theory aims to model some phenomena and } \\
\text { its action in a scientific way." (101) }\end{array}$ & $\begin{array}{l}\text { "Theory is a view of some certain topic and it's developed } \\
\text { through research or researchers. This topic is aimed to } \\
\text { explain with the help of theory." (111) } \\
\text { "Theory is a conceptual view of some phenomena or topic } \\
\text { and it's based on research. Theory is a model based } \\
\text { description developed by one or several people and it } \\
\text { describes the different aspects of the topic and the } \\
\text { interaction between these aspects." (112) }\end{array}$ & \\
\hline
\end{tabular}

TABLE 3 | Students' conceptions of theory.
Number of answers

Everyday conceptions

Declarative leve

Procedural level

Epistemic level
Percent

(\%) of answers

$53.6 \%$

$20.6 \%$

$18.4 \%$

$7.4 \%$
1) Conceptions of theory at the declarative level: some of the students described the concept of theory by using some terms that were related to science, for example the term scientific.

2) Conceptions of theory at the procedural level: some of the students showed understanding of where theories come from, and what theories can be used for. Their answers were related to research and "doing".

3) Conceptions of theory at an epistemic level: some of the students showed epistemic views in their answers. For example, understanding that theories are pursued through scientific research by researchers using different research methods and that scientific knowledge is uncertain, unstable and created by people.

As noted earlier, we assumed that the levels of understanding, that is, declarative, procedural and epistemic are hierarchical in nature. Thus, the answers were analysed by interpreting that in which of these levels each student is currently able to describe the concept. Examples of students' answers in these categories are presented in Table 2.

The total number of students' answers classified to each category is presented in Table 3. Strengthening our assumption about the complex nature of the concept of theory, the analysis revealed that over half (53.6\%) of all the students' were not able to report their conception of theory in a scientific context. When looking at the scientific conceptions, only a few students showed understanding of the concept at the epistemic level. About one fifth of the students were able to describe the concept at procedural level and about the same number of students at the declarative level.

\section{Conceptions of Theory Between Early Stage Students and Graduating Students}

To find out if there are differences between conceptions of students in different phases of their studies, we compared early stage (first and second year) students' and graduating (fourth and fifth year) students' answers. Early stage students had more non-scientific conceptions $(65.40 \%)$ than graduating students, but it is noteworthy, that a little under half $(44.10 \%)$ of all graduating students did not show a scientific understanding of the concept. When looking at the scientific conceptions, only a small number of graduating students $(8.50 \%)$ and early stage students $(7.50 \%)$ showed understanding about the concept at the epistemic level. The result strengthens our assumption that reaching the epistemic level might not be very typical for university students. About one fifth of both graduating students (22\%) and early stage students (18.7\%) demonstrated a procedural approach meaning that they were able to describe theory related to research and "doing. The number of graduating students in this level would have been assumed to be higher. On the other hand, this confirms the complex nature of the concept of theory in learning. About one quarter (25.4\%) of graduating students and few early stage students (8.4\%) showed understanding the concept of theory in declarative level, i.e. were able to use some scientific terms in their answers. The differences between students' conceptions are presented in Figure 2. 


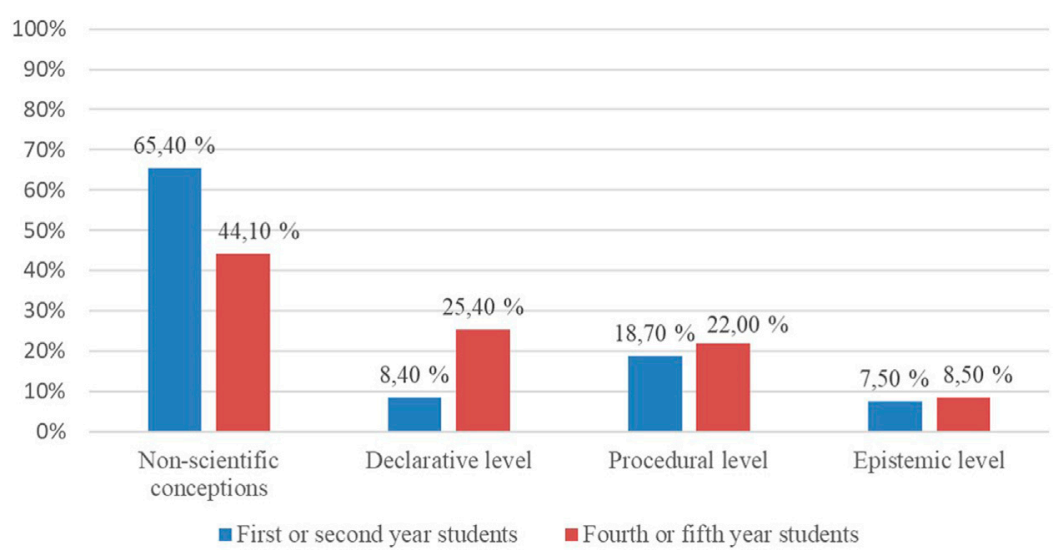

FIGURE 2 | Differences in conceptions of theory between first and second year students and Master's degree students.

\section{DISCUSSION}

The aim of this study was to increase our understanding of teacher education students' research competence by exploring how they understand the concept of theory. The results of this study are in line with previous studies (Murtonen, Aiston \& Kiley 2006; Kiley \& Wisker, 2009; Murtonen, 2015; Earley, 2014; Wagner, Garner \& Kawulich, 2011) showing that students face problems in learning research skills and understanding the most central scientific concepts such as empirical and theorethical (Murtonen, 2015). According to our findings, over half of the students' were not able to describe the concept of theory in a scientific context meaning that under half of the students demonstrated a scientific understanding of the concept. Early stage (first and second year) students reported more non-scientific conceptions than graduating (fourth and fifth year) students, but what was quite worrying, almost half of the graduating students didn't report scientific conceptions of the concept of theory meaning, that they understood, or were able to report the concept in non-scientific context. The finding is significant, because we assume that understanding the most central scientific concepts, like the concept of theory in this case, is crucial for the development of more advances research skills.

The analysis of the scientific conceptions that students had reported revealed, that only a few of the students, regardless of their study phase, showed an understanding the concept at the most advanced, epistemic level. This is quite understandable, because understanding the nature and origins of scientific knowledge is a sophisticated skill. This understanding applies to scientific knowledge and an understanding of the fundamental origins of scientific knowledge that develops hand in hand with experience, practice and expertise. About one fifth of both early stage and graduating students showed that they understood the concept of theory at a procedural level, meaning that they saw it related to research and doing. We assume that this level is needed to reach to be able to utilise and understand research results, and also possibly participate in scientific knowledge construction. This is already very advanced and we suppose that a lot of practice and experience is needed to be able to reach this level. One quarter of graduating students were able to describe theory at a declarative level meaning that they had skills to describe the concepts in some basic scientific level by using some scientific terms. The number of early stage students in this level was clearly lower than graduating students, suggesting that graduating students might have learned to understand the concept in declarative level during their studies. That is a starting point to be able to move forward to more advanced levels in a scientific context.

There are some limitations concerning the data and the method used in this study. The data was collected by asking students to answer a simple open-ended question and many of the students' answers were quite short and possibly superficial. Thus, it could be argued that the method was not sufficiently multifaceted to be able to gain a truly deep understanding of students' thinking. When comparing answers that were categorised to different categories, the answers that showed non-scientific conceptions were typically shorter than the answers categorised to the scientific conceptions. The reason might be, that these students' really didn't have much to say, because the question is very difficult to answer if you don't understand the scientific meaning of the concept. More advanced methods, for example interviews would have given us much deeper understanding of students thinking. In the future, different and more advanced research methods could be used to deepen understanding of the topic. For example, interviews would allow to get deeper to participant thoughts. The data of this study consisted only of teacher education students. Exploring their research competence is important, because teachers' own research learning experiences are related their teaching strategies that they use in their own teaching (Brew \& Saunders, 2020). In the future, also disciplinary differences could be explored.

The findings of this study provide important information for university teachers and perspectives for future research. If half of the students understand the concept of theory in nonscientific context, more attention needs to be paid to the methods of how these kinds of central scientific concepts are taught at universities. Also, teachers are not always necessarily aware of the problems that their students face with learning these conceptions especially if the learning outcomes are 
measured only in the end of the course. Exploring what kind of pre-conceptions students have about the most central concepts would be important to be able to support their learning. For example, if students' conceptions of theory seems to be related more to everyday thinking than the meaning of the concept in scientific context, teacher is able to consider what are the best pedagogical solutions to support students' learning, or 'help students over possible barriers', as Balloo (2019) argues. Also, more attention needs to be paid to teachers' approaches to supporting their students to learn these central scientific concepts. Not all the teachers see the development of their students' research competence as important as do others and this can be related to their way of teaching (Brew \& Mantai, 2017; Brew \& Saunders, 2020).

In the future, more advanced research methods could be used to deepen our understanding of the topic from the viewpoint of university students. For example, interviews would allow researchers to gain a deeper understanding of students' conceptions. In addition, it would be important to also explore the topic from the viewpoint of university teachers to find out 1) how explicitly they aim to teach central scientific concepts, such as the concept of theory, 2) how aware they are of the various level of their students' understanding these concepts and 3) how, and in which phases of their courses or study years students understanding is evaluated.

\section{REFERENCES}

Balloo, K. (2019). “Students' Difficulties during Research Methods Training Acting as Potential Barriers to Their Development of Scientific Thinking," in Redefining Scientific Thinking for Higher Education. Editors M. Murtonen and K. Balloo (Cham: Palgrave Macmillan). doi:10.1007/978-3-030-24215-2_5

Böttcher, F., and Thiel, F. (2018). Evaluating Research-Oriented Teaching: a New Instrument to Assess university Students' Research Competences. High Educ. 75 (1), 91-110. doi:10.1007/s10734-017-0128-y

Brew, A., and Mantai, L. (2017). Academics' Perceptions of the Challenges and Barriers to Implementing Research-Based Experiences for Undergraduates. Teach. Higher Edu. 22 (5), 551-568. doi:10.1080/13562517.2016.1273216

Brew, A., and Saunders, C. (2020). Making Sense of Research-Based Learning in Teacher Education. Teach. Teach. Edu. 87, 102935. doi:10.1016/ j.tate.2019.102935

Chang, H.-P., Chen, C.-C., Guo, G.-J., Cheng, Y.-J., Lin, C.-Y., and Jen, T.-H. (2011). The Development of a Competence Scale for Learning Science: Inquiry and Communication. Int. J. Sci. Math. Educ. 9 (5), 1213-1233. doi:10.1007/ s10763-010-9256-x

Earley, M. A. (2014). A Synthesis of the Literature on Research Methods Education. Teach. Higher Edu. 19 (3), 242-253. doi:10.1080/13562517.2013.860105

Hyytinen, H., Toom, A., and Shavelson, R. J. (2019). "Enhancing Scientific Thinking through the Development of Critical Thinking in Higher Education," in Redefining Scientific Thinking for Higher Education: HigherOrder Thinking, Evidence-Based Reasoning and Research Skills. Editors M. Murtonen and K. Balloo (Cham: Palgrave Macmillan). doi:10.1007/9783-030-24215-2_3

J. H. F. Meyer and R. Land (Editors) (2006). Overcoming Barriers to Student Understanding: Threshold Concepts and Troublesome Knowledge (Abingdon: Routledge).

Kiley, M. (2015). 'I Didn't Have a Clue what They Were Talking about': PhD Candidates and Theory. Innov. Edu. Teach. Int. 52 (1), 52-63. doi:10.1080/ 14703297.2014.981835

Kiley, M. (2019). "Threshold Concepts of Research in Teaching Scientific Thinking," in Redefining Scientific Thinking for Higher Education: Redefining

\section{DATA AVAILABILITY STATEMENT}

The raw data supporting the conclusions of this article will be made available by the authors, without undue reservation.

\section{ETHICS STATEMENT}

Ethical review and approval was not required for the study on human participants in accordance with the local legislation and institutional requirements. The patients/participants provided their written informed consent to participate in this study.

\section{AUTHOR CONTRIBUTIONS}

HS, MM, and MK contributed to the design of the study. HS collected the data, organized the database, performed the statistical analysis and drafted the initial manuscript. HS, MM, and $\mathrm{MK}$ contributed to components of the manuscript, and on the basis of that HS finished the article. All authors contributed to manuscript revisions and read, and approved the submitted version.

Scientific Thinking for Higher Education: Higher-Order Thinking, EvidenceBased Reasoning and Research Skills. Editors M. Murtonen and K. Balloo (Palgrave Macmillan). doi:10.1007/978-3-030-24215-2_6

Kiley, M., and Wisker, G. (2009). Threshold Concepts in Research Education and Evidence of Threshold Crossing. Higher Edu. Res. Dev. 28 (4), 431-441. doi:10.1080/07294360903067930

Knight, R. (2015). Postgraduate Student Teachers' Developing Conceptions of the Place of Theory in Learning to Teach: 'more Important to Me Now Than when I Started'. J. Edu. Teach. 41 (2), 145-160. doi:10.1080/02607476.2015.1010874

Kuhn, D., and Pearsall, S. (2000). Developmental Origins of Scientific Thinking J. Cogn. Dev. 1 (1), 113-129. doi:10.1207/s15327647jcd0101n_11

Kuhn, D., and Weinstock, M. (2002). "What Is Epistemological Thinking and Why Does it Matter," in Personal Epistemology: The Psychology of Beliefs about Knowledge and Knowing. Editors B. Hofer and P. Pintrich (Mahwah, New Jersey: Lawrence Erlbaum Associates), 121-144.

Kuhn, D. (2010). "What Is Scientific Thinking and How Does it Develop," in Handbook of Childhood Cognitive Development. Editor U. Goswami. 2nd ed. (Oxford: Blackwell), 497-523. doi:10.1002/9781444325485.ch19

Lorencová, H., Jarošová, E., Avgitidou, S., and Dimitriadou, C. (2019). Critical Thinking Practices in Teacher Education Programmes: a Systematic Review. Stud. Higher Edu. 44 (5), 844-859. doi:10.1080/ 03075079.2019.1586331

Murtonen, M., Aiston, S., and Kiley, M. (2006). "Research Candidates' Conceptions of Theory," in Quality in Postgraduate Research: Knowledge Creation in Testing Times. Editors M. Kiley and G. Mullins (Canberra: CEDAM, The Australian National University), 141-148.

Murtonen, M., and Balloo, K. (2019). "Preface," in Redefining Scientific Thinking for Higher Education: Higher-Order Thinking, Evidence-Based Reasoning and Research Skills. Editors M. Murtonen and K. Balloo (Palgrave Macmillan).

Murtonen, M., Olkinuora, E., Tynjälä, P., and Lehtinen, E. (2008). "Do I Need Research Skills in Working Life?": University Students' Motivation and Difficulties in Quantitative Methods Courses. High Educ. 56, 599-612. doi:10.1007/s10734-008-9113-9

Murtonen, M., and Salmento, H. (2019). "Broadening the Theory of Scientific Thinking for Higher Education," in Redefining Scientific Thinking for Higher Education: Higher-Order Thinking, Evidence-Based Reasoning and Research 
Skills. Editors M. Murtonen and K. Balloo (Palgrave Macmillan). doi:10.1007/ 978-3-030-24215-2_1

Murtonen, M. (2015). University Students' Understanding of the Concepts Empirical, Theoretical, Qualitative and Quantitative Research. Teach. Higher Edu. 20 (7), 684-698. doi:10.1080/13562517.2015.1072152

Nussbaum, E. M., Sinatra, G. M., and Poliquin, A. (2008). Role of Epistemic Beliefs and Scientific Argumentation in Science Learning. Int. J. Sci. Edu. 30 (15), 1977-1999. doi:10.1080/09500690701545919

Puustinen, M., Säntti, J., Koski, A., and Tammi, T. (2018). Teaching: A Practical or Research-Based Profession? Teacher Candidates' Approaches to ResearchBased Teacher Education. Teach. Teach. Edu. 74, 170-179. doi:10.1016/ j.tate.2018.05.004

Salmento, H., and Murtonen, M. (2019). "The Roles of Epistemic Understanding and Research Skills in Students' Views of Scientific Thinking," in Redefining Scientific Thinking for Higher Education: Higher-Order Thinking, Evidence-Based Reasoning and Research Skills. Editors M. Murtonen and K. Balloo (Palgrave Macmillan). doi:10.1007/ 978-3-030-24215-2_2

Thiel, F., and Böttcher, F. (2014). "Modellierung fächerübergreifender Forschungskompetenzen. Das RMKR-W-Modell als Grundlage der Planung und Evaluation von Formaten forschungsorientierter Lehre," in Neues Handbuch Hochschullehre. Lehren und Lernen effizient gestalten. [Teil] I. Evaluation. Fachbereichs-/Studiengangsevaluation. Editors B. Berendt, H.-P. Voss, and J. Wildt (Berlin: Raabe), 1-124.

Tight, M. (2015). Theory Development and Application in Higher Education Research: The Case of Academic Drift. J. Educ. Adm. Hist. 47 (1), 84-99. doi:10.1080/00220620.2015.974143
Valter, K., and Akerlind, G. (2010). Introducing Students to Ways of Thinking and Acting like a Researcher: a Case Study of Research-Led Education in the Sciences. Int. J. Teach. Learn. Higher Edu. 22 (1), 89-97.

van Katwijk, L., Berry, A., Jansen, E., and van Veen, K. (2019). "It's Important, but I'm Not Going to Keep Doing it!": Perceived Purposes, Learning Outcomes, and Value of Pre-service Teacher Research Among Educators and Pre-service Teachers. Teach. Teach. Edu. 86, 102868. doi:10.1016/j.tate.2019.06.022

Wagner, C., Garner, M., and Kawulich, B. (2011). The State of the Art of Teaching Research Methods in the Social Sciences: towards a Pedagogical Culture. Stud. Higher Edu. 36 (1), 75-88. doi:10.1080/03075070903452594

Conflict of Interest: The authors declare that the research was conducted in the absence of any commercial or financial relationships that could be construed as a potential conflict of interest.

Publisher's Note: All claims expressed in this article are solely those of the authors and do not necessarily represent those of their affiliated organizations, or those of the publisher, the editors and the reviewers. Any product that may be evaluated in this article, or claim that may be made by its manufacturer, is not guaranteed or endorsed by the publisher.

Copyright $(\odot 2021$ Salmento, Murtonen and Kiley. This is an open-access article distributed under the terms of the Creative Commons Attribution License (CC BY). The use, distribution or reproduction in other forums is permitted, provided the original author(s) and the copyright owner(s) are credited and that the original publication in this journal is cited, in accordance with accepted academic practice. No use, distribution or reproduction is permitted which does not comply with these terms. 